\title{
$=U$ ESTUDOS
}

Revista de Cultura da UFPE

\section{Ensaio Visual}

Texto submetido em: 17 mar. 2021. Aprovado em: 28 maio 2021.

BORRE, Luciana. Desobediência: uma intervenção urbana com a Pedagogia da Autonomia. Estudos Universitários: revista de cultura, UFPE/Proexc, Recife, v. 38, n. 1, p. 477-488, jan./jun., 2021.

DOI: $10.51359 / 2675-7354.2021 .249913$

ISSN Edição Digital: 2675-7354

\section{(cc) BY}

Esta obra está licenciada com uma Licença Creative Commons Atribuição 4.0 Internacional. 


\section{Desobediência: uma intervenção urbana com a Pedagogia da Autonomia}

Disobedience: an urban intervention with Pedagogia da Autonomia

\section{Luciana Borre}

Universidade Federal de Pernambuco (UFPE)

Doutora em Arte e Cultura Visual

E-mail: lucianaborre@yahoo.com.br

(D) https://orcid.org/0000-0002-1929-3734

\section{Resumo}

Apresento a intervenção urbana "Desobediência" (2019) e suas repercussões no campo da formação de professoras/es que atuam para/ com as infâncias e juventudes. Narro visualmente processos de ensino e de aprendizagem compartilhados com estudantes do curso de Artes Visuais-Licenciatura, da Universidade Federal de Pernambuco (UFPE), nas perspectivas da Educação da Cultura Visual. Parto de relatos pessoais e da intervenção poética na obra Pedagogia da Autonomia, de Paulo Freire (2002), para ressignificar trajetórias como professores artistas a partir da seguinte pergunta: "Como narrativas autobiográficas ecoam nos processos de ensinar, aprender e artistar?".

Palavras-chave: Cultura visual. Formação docente. Paulo Freire.

\section{Abstract}

I present the urban intervention "Desobediência" (2019) and its repercussions in the field of training visual arts teachers, who work with children and teenagers. I report teaching and learning processes shared with Visual Arts - Teaching Major students at Universidade Federal de Pernambuco (UFPE) in the Visual Culture Education perspective. I start from a personal 
account and from the poetic intervention of the book Pedagogia da Autonomia, by Paulo Freire (2002) to reframe our trajectories as artist teachers, asking: "How do my autobiographical narratives reflect in the processes of teaching, learning and artistar?".

Keywords: Visual culture. Teacher training. Paulo Freire.

“Desobediência” (2019) foi uma intervenção urbana através da qual a professora Luciana Borre e seus estudantes de Licenciatura em Artes Visuais, da Universidade Federal de Pernambuco (UFPE), interferiram imageticamente nas páginas do livro Pedagogia da Autonomia, de Paulo Freire (2002), tornando tal material um lambe-lambe fixado em diversos pontos da cidade do Recife, Pernambuco. A leitura da obra e sua posterior ressignificação visual estão inscritas nas práticas contemporâneas em Artes Visuais, provocando os seguintes questionamentos entre os integrantes do grupo: "Como nossas narrativas autobiográficas ecoam nos processos de ensinar, aprender e artistar a partir de Paulo Freire? Como tornarmo-nos professoras/es inventivas/os diante de tantos processos artísticos e pedagógicos reguladores? Quais as possíveis vulnerabilidades e riscos nos processos inventivos de ensinar? Como nossas práticas artísticas e a leitura da obra de Paulo Freire podem reverberar na formação docente? Como nos vemos no cenário artístico-pedagógico contemporâneo e como isso influencia a identidade docente?". A intervenção urbana com as páginas do livro de Paulo Freire, narrada neste ensaio visual, foi tratada como movimento desobediente e potencializador de novos eventos para/na educação básica, a fim de que "o educando mantenha vivo em si o gosto da rebeldia, aguçando sua curiosidade e estimulando sua capacidade de arriscar-se, de aventurar-se, que de certa forma o 'imuniza' contra o poder apassivador do 'bancarismo'” (FREIRE, 2002, p. 27). 


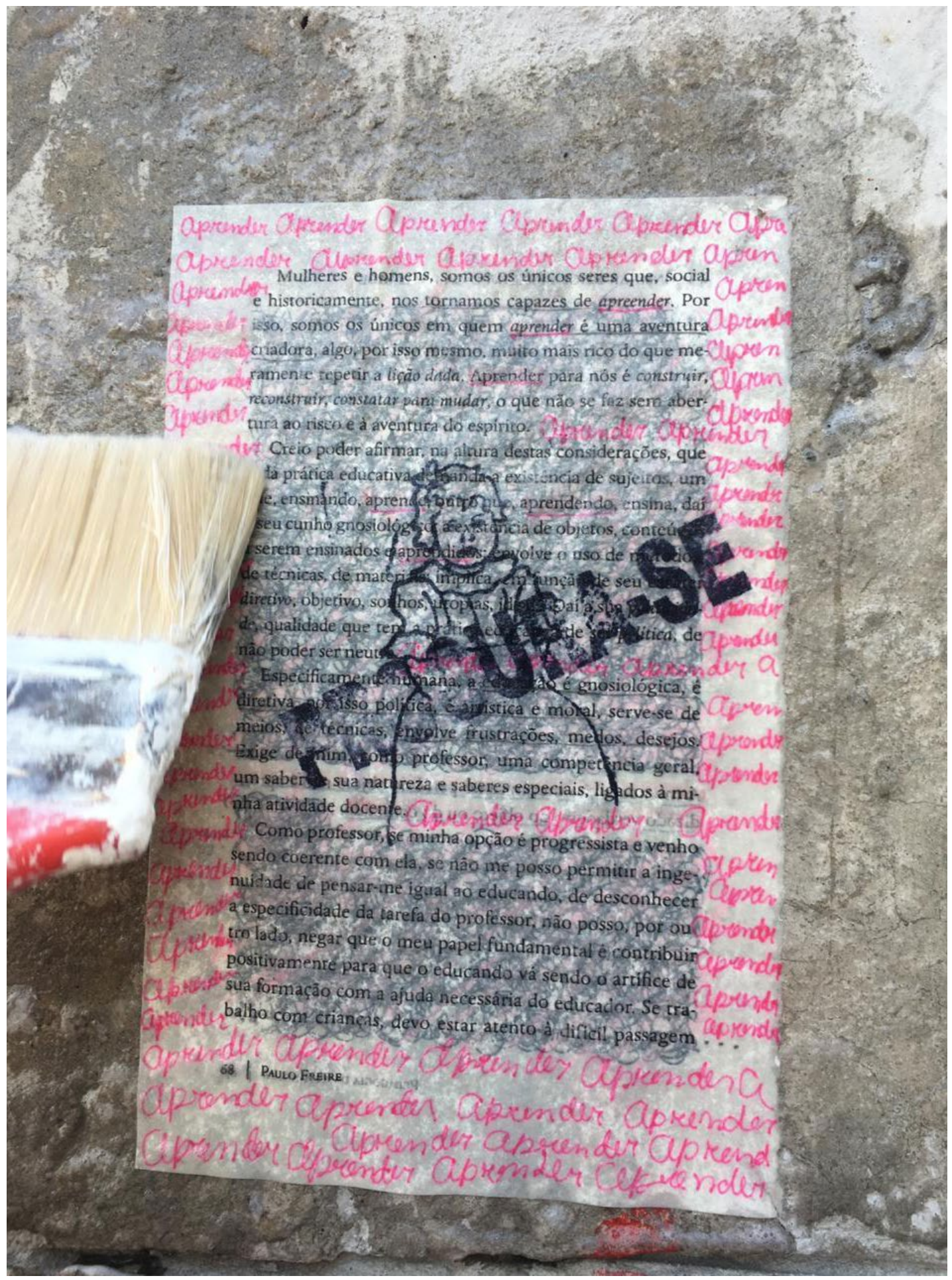




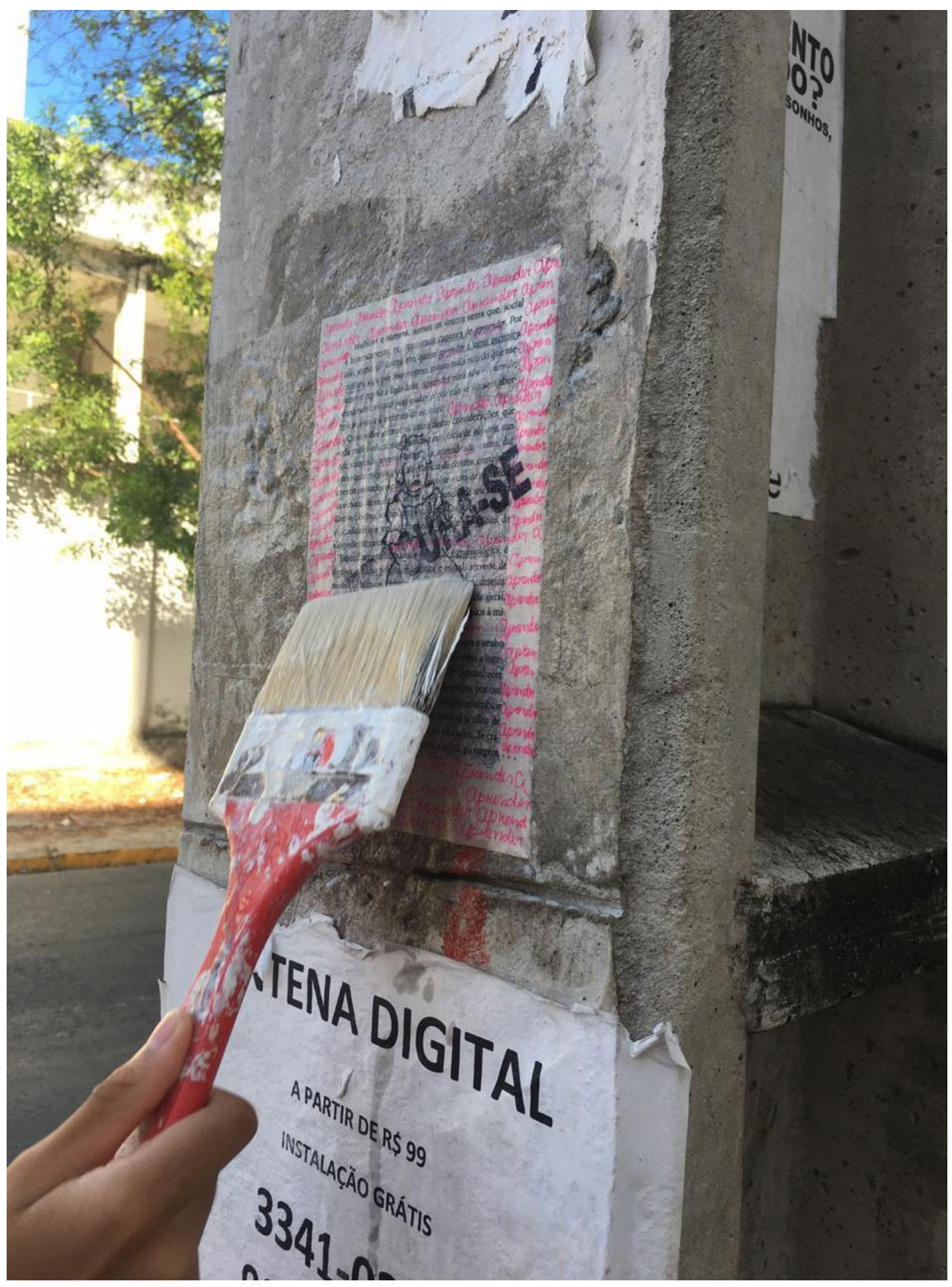




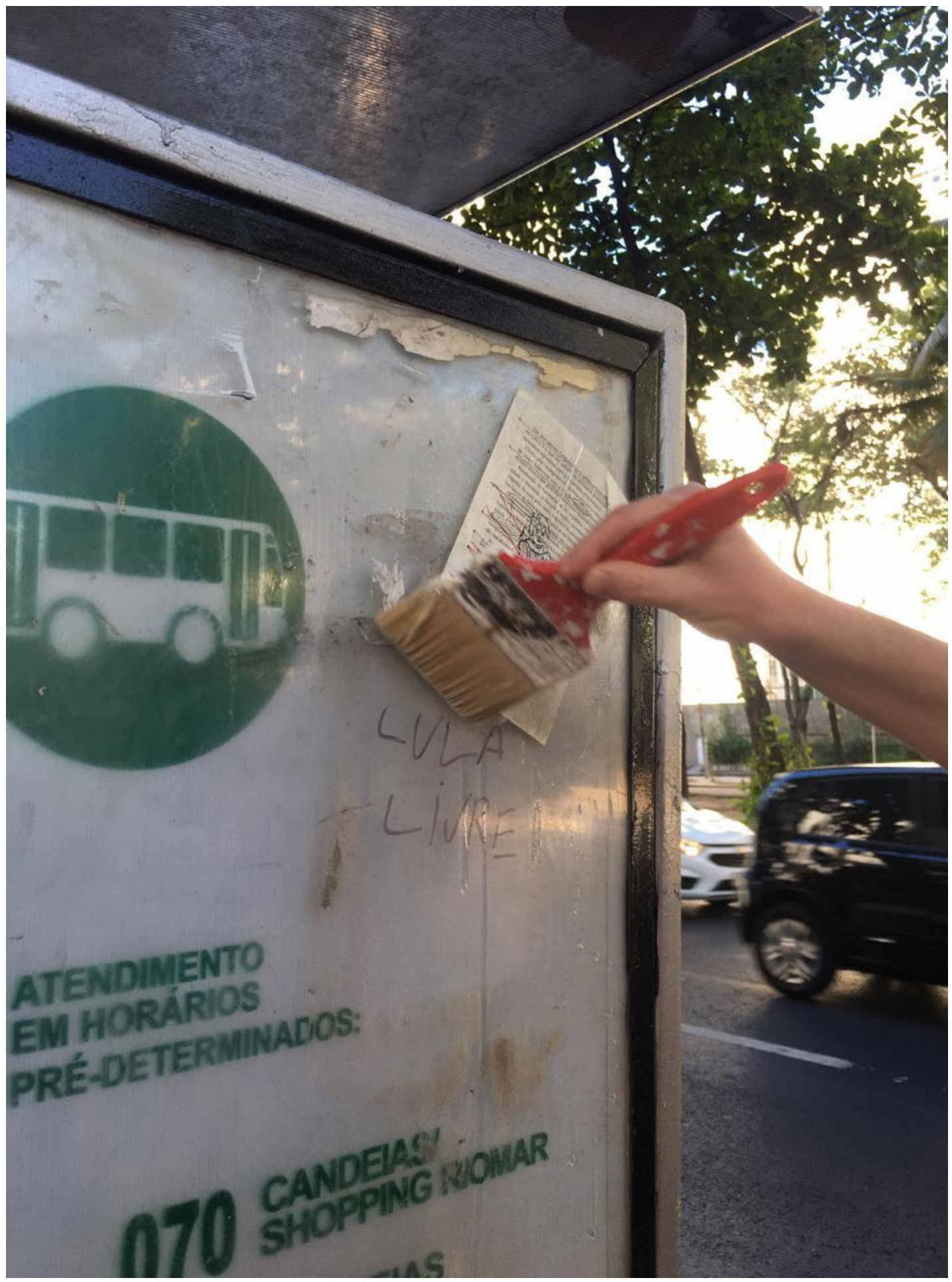




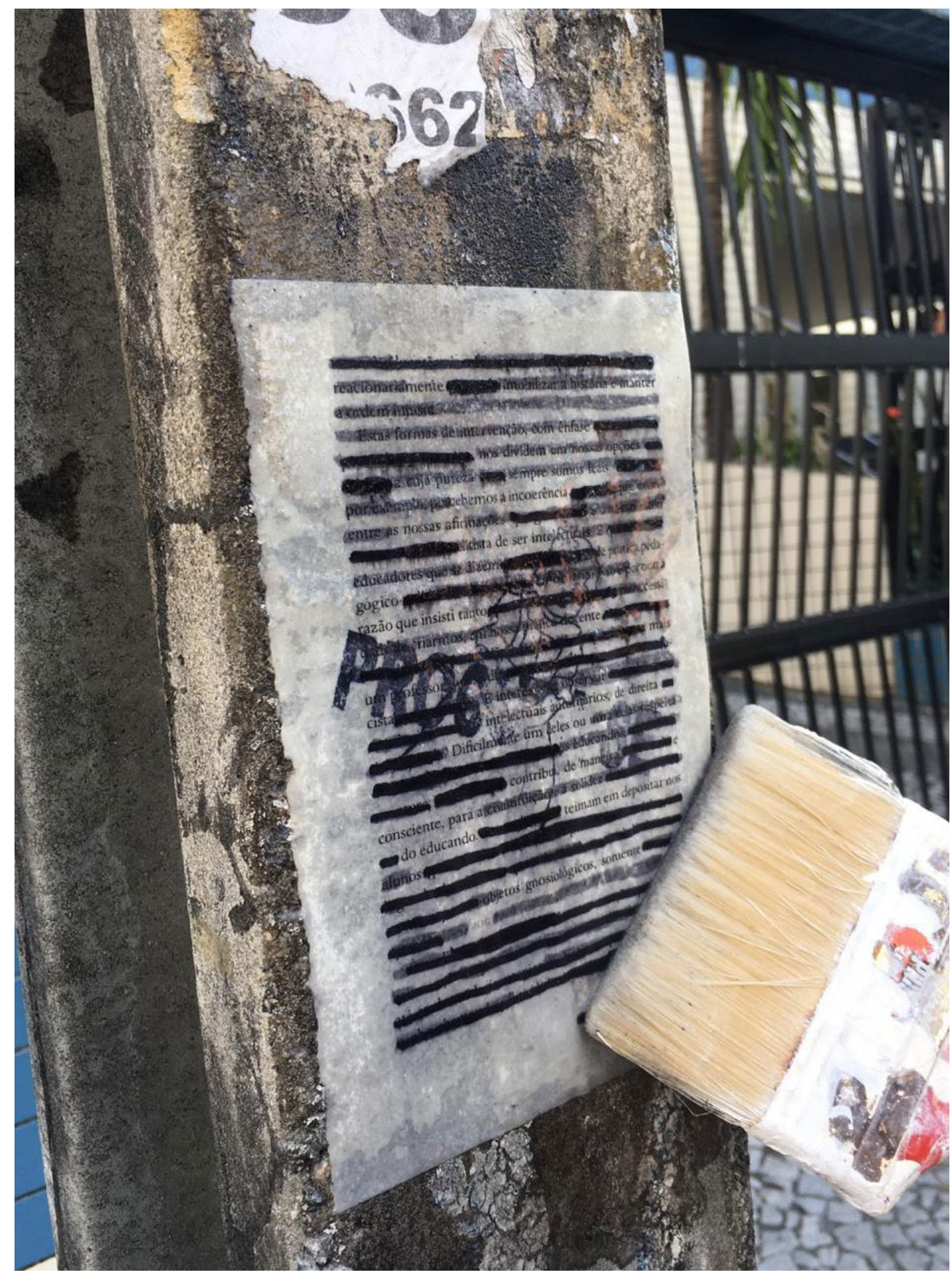




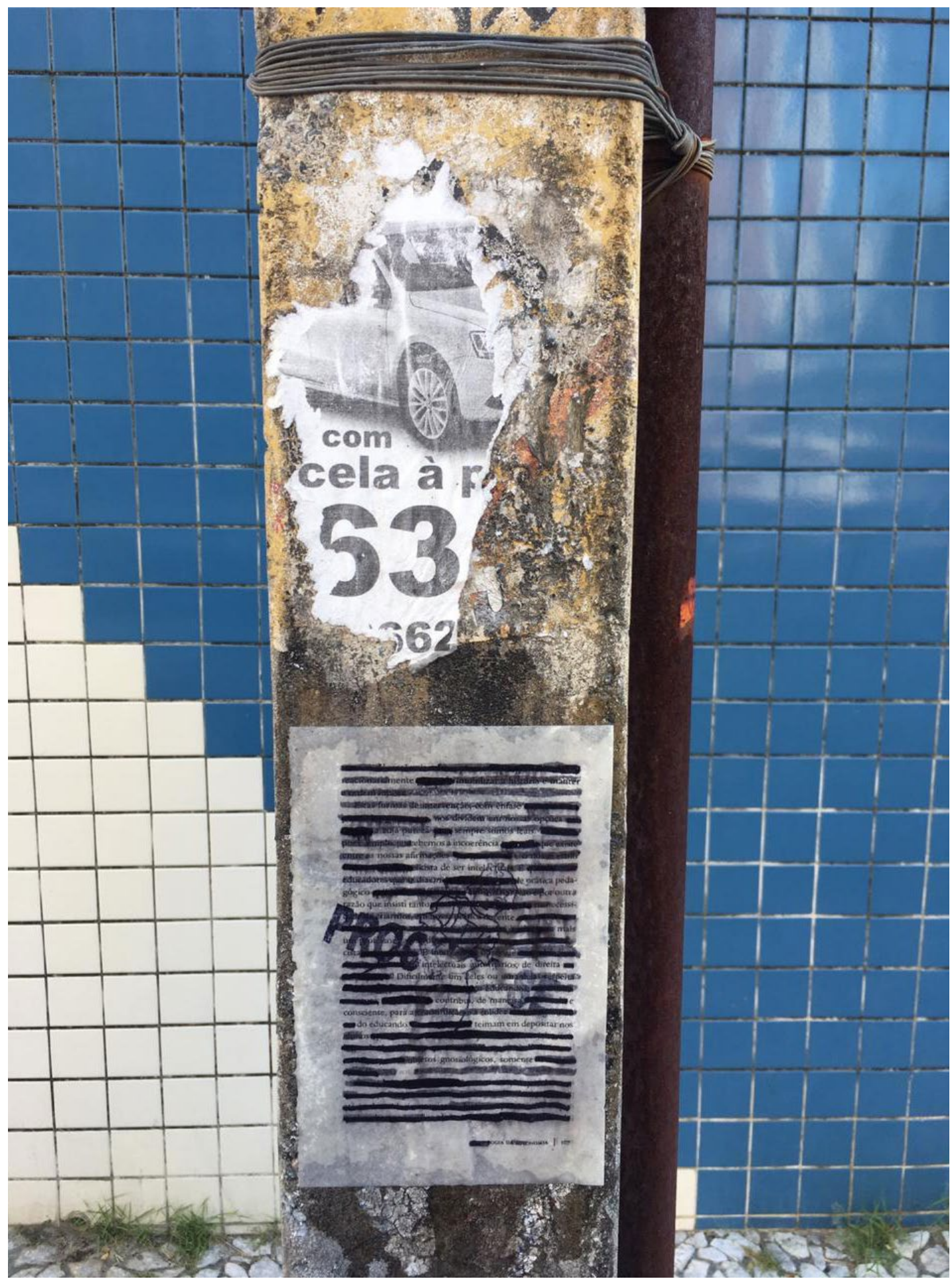




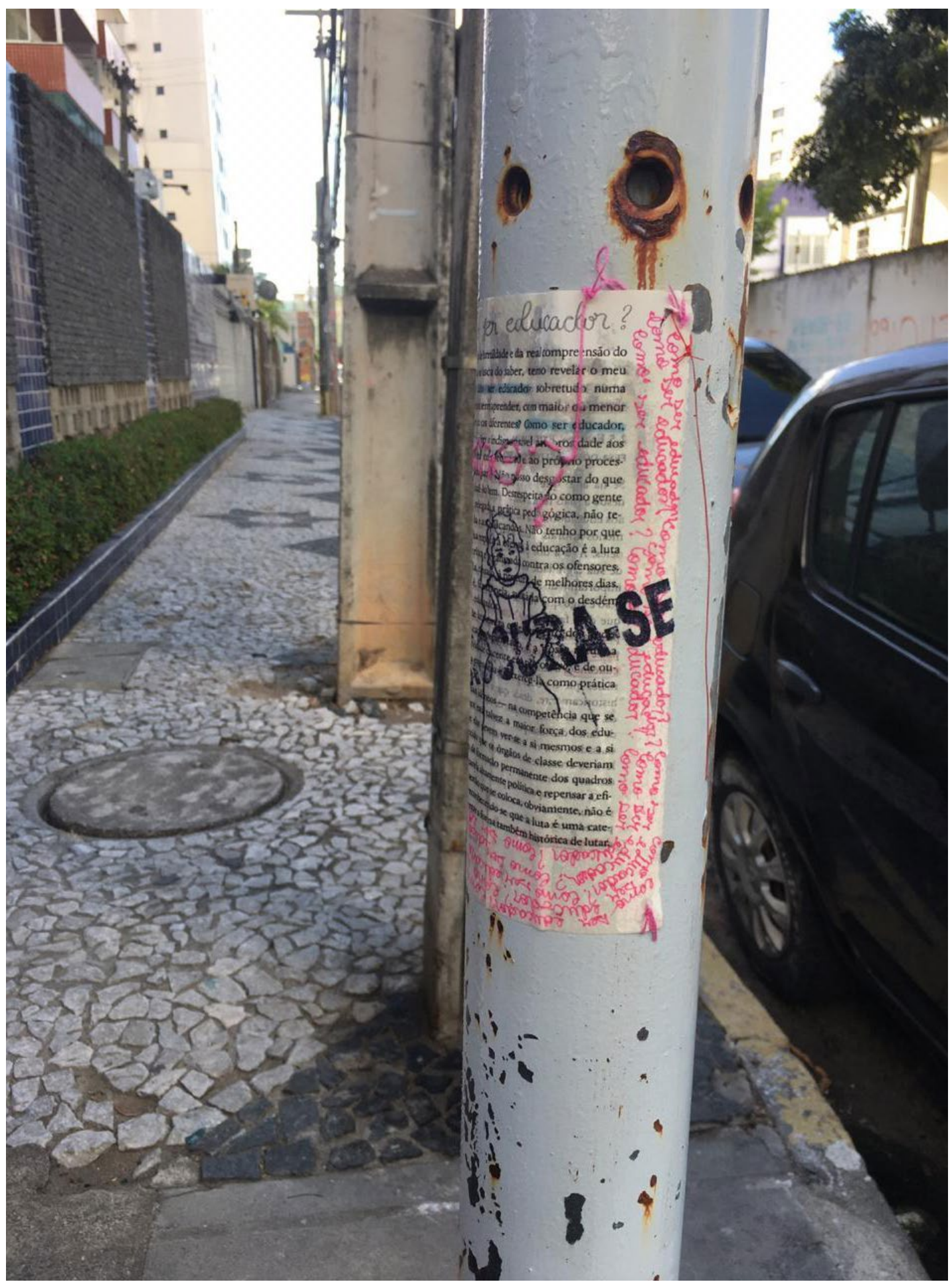




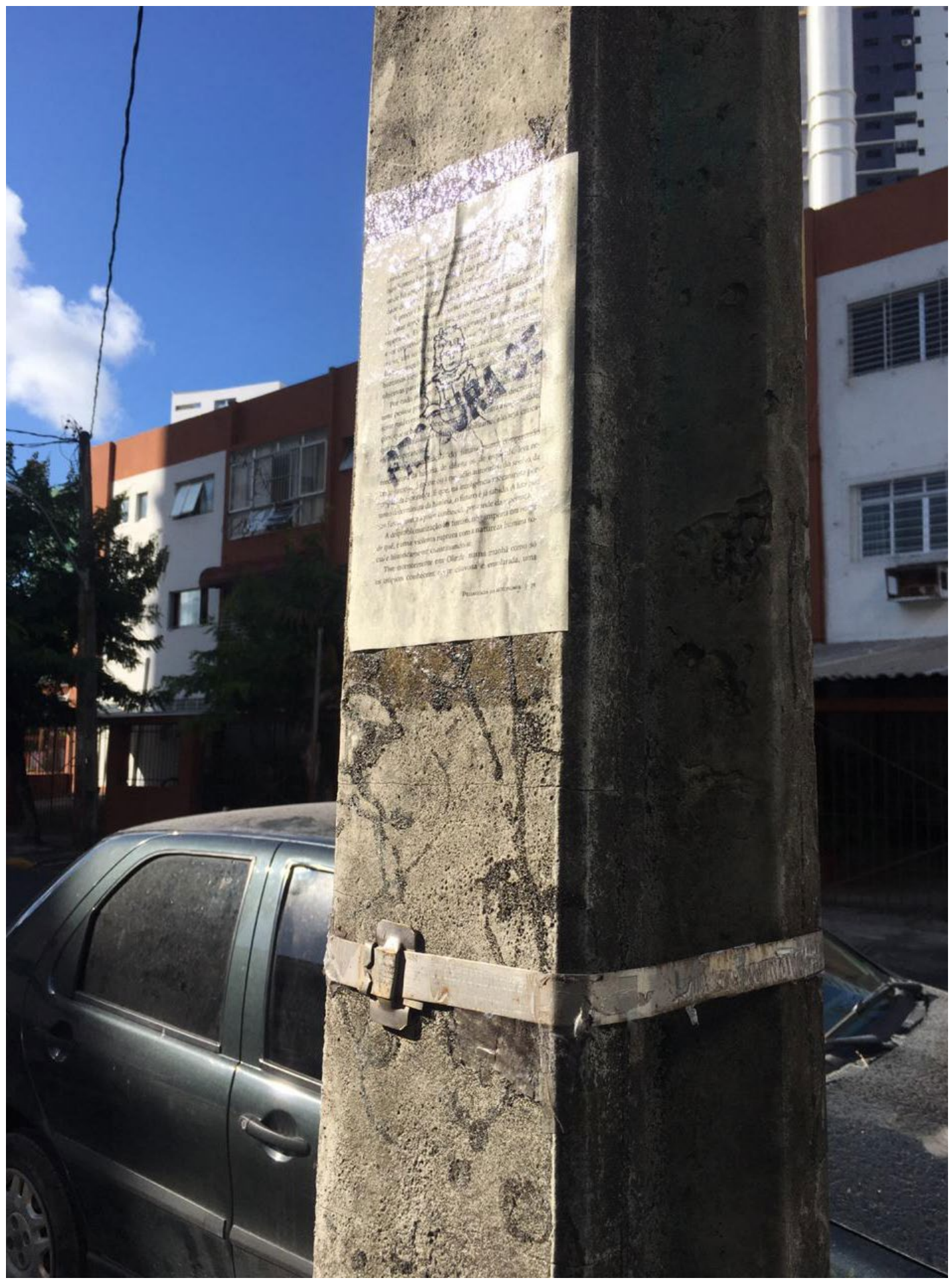




\section{Referências}

$\angle A M B E-L A M B E$ - intervenção urbana. Fotografias de Luciana Borre.

Recife, 2019.

FREIRE, Paulo. Pedagogia da autonomia: saberes necessários à prática

educativa. São Paulo: Paz e Terra, 2002. 


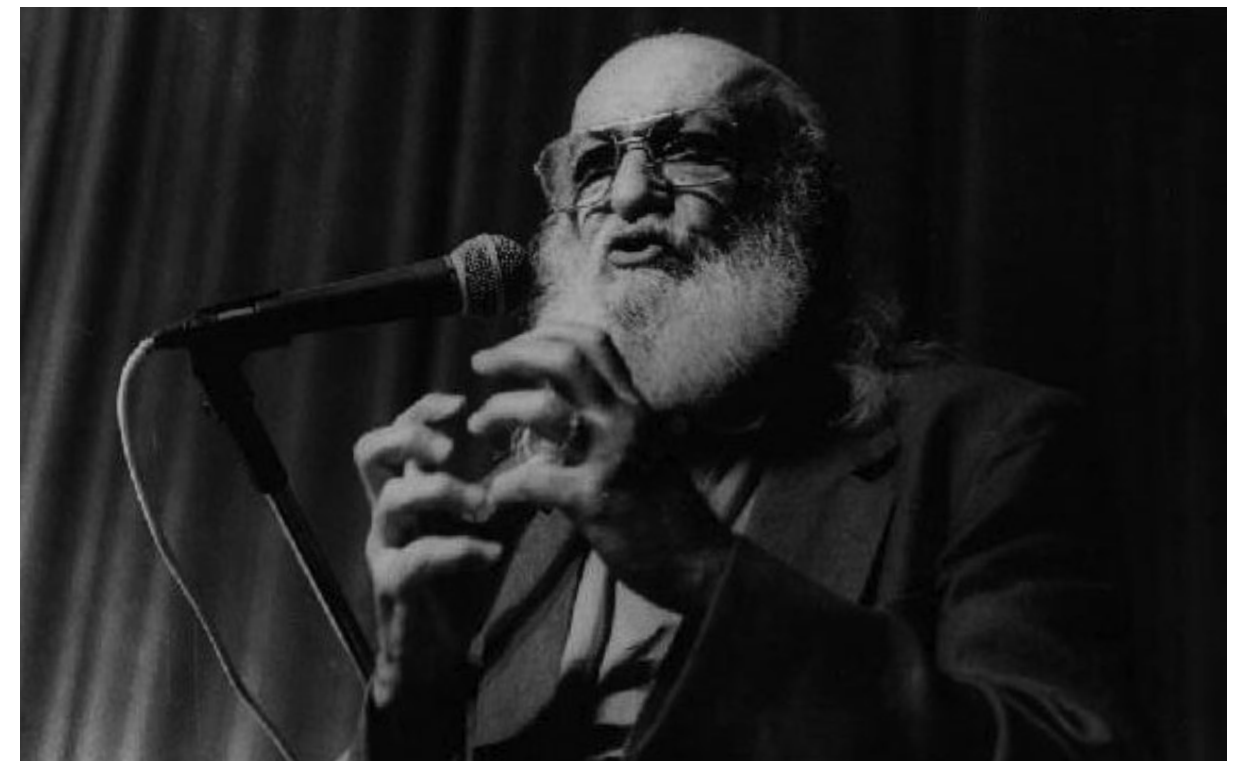

Paulo Freire fala ao microfone em evento não identificado. Assessoria de Comunicação Social da UFPE. 